\title{
Identificación de cepas bacterianas cultivables presentes en peces (caballas) utilizando un fragmento del gen $16 \mathrm{~S} \mathrm{ARNr}$
}

\author{
Pulache, I.; Ordinola, A.; Vieyra, E.; Mendoza, O. \\ Facultad Ingeniería Pesquera y Ciencias del Mar, Universidad \\ Nacional de Tumbes, Perú. E-mail: oscarmendoza7@gmail.com
}

\begin{abstract}
Resumen
Pulache, I., Ordinola, A.; Vieyra, E.; Mendoza, O.: Identificación de cepas bacterianas cultivables presentes en peces (caballas) utilizando un fragmento del gen I6S ARNr. Rev. Vet. 32: 1, 68-72, 2021. El salazonado de pescado es una forma antigua y económica de preservación que se usa aún en países en vías de desarrollo como el Perú. En la región Tumbes, es común la comercialización de caballa (Scomber japonicus peruanus) salada artesanalmente, por lo cual su inocuidad microbiológica no está garantizada. La presente investigación tuvo como objetivo identificar, mediante el secuenciamiento de un fragmento del gen 16S ARNr, las bacterias cultivables presente en la caballa salada comercializada en Tumbes. A partir de tejido del músculo de la caballa, se aislaron cepas bacterianas en medio TSA suplementado con $15 \%$ de $\mathrm{NaCl}$, de las que luego se obtuvieron fragmentos del gen $16 \mathrm{~S} \mathrm{ARNr}$, que fueron secuenciados para luego identificar la especie a la que pertenecieron mediante una búsqueda en Genbank. Adicionalmente se analizaron el contenido de humedad y de $\mathrm{NaCl}$ del músculo de la caballa salada. Como resultado se identificaron cepas típicas de productos salados como: Staphylococcus sp, Halomonas sp. Staphylococcus equorum, Salinivibrio sp, Staphylococcus nepalensis y Salinivibrio sp. Sin embargo, en el 70\% de las caballas analizadas se tuvieron niveles de humedad inadecuados, así como bajos niveles de $\mathrm{NaCl}$, lo cual indicó un salado inadecuado y en consecuencia un producto con pobre conservación.
\end{abstract}

Palabras clave: Scomber japonicus, pescado salado, genómica, bacterias, gen 16S ARNr.

\begin{abstract}
Pulache, I., Ordinola, A.; Vieyra, E.; Mendoza, O.: Identification of cultivable bacterial strains present in Scomber japonicus peruanus salted using a fragment of the $16 \mathrm{~S}$ rRNA gene. Rev. Vet. 32: 1, 68-72, 2021. Salting fish is an ancient and economical form of preservation that is still used in developing countries such as Peru. In the Tumbes region, it is common the commercialization of mackerel (Scomber japonicus peruanus) salted by hand, so its microbiological safety is not guaranteed. The investigation aimed to identify, by sequencing a fragment of the 16S rRNA gene, the cultivable bacteria present in salted mackerel marketed in Tumbes. From mackerel muscle tissue, bacterial strains were isolated in TSA medium supplemented with $15 \% \mathrm{NaCl}$, from which fragments of the $16 \mathrm{~S}$ rRNA gene were obtained and sequenced to identify the species to which they belonged through a search in Genbank. Additionally, the moisture and $\mathrm{NaCl}$ content of the salted mackerel muscle were analyzed. As a result, typical strains of salted products were identified such as Staphylococcus sp, Halomonas sp, Staphylococcus equorum, Salinivibrio sp, Staphylococcus nepalensis, and Salinivibrio sp. However, in $70 \%$ of mackerels analyzed, there were inadequate humidity levels, as well as low levels of $\mathrm{NaCl}$ that indicated an inadequate salting and consequently a product of poor conservation.
\end{abstract}

Keywords: Scomber japonicus, salted fish, genomics, bacteria, 16S ARNr gene.

\section{INTRODUCCIÓN}

Scomber japonicus peruanus (Jordan \& Hubbs, 1925), es una especie cosmopolita que en Perú y otros países se conoce como caballa. Habita en ambientes relativamente cálidos, a temperatura del agua entre $14^{\circ} \mathrm{C}$ y $23^{\circ} \mathrm{C}$, y salinidad de $34,9 \%$ a $35,2 \%$. En el Perú es la tercera especie más desembarcada ${ }^{1,2}$.

Gran parte de su captura se procesa como salado y se comercializa en lugares donde existe fuerte demanda, como en Tumbes, donde además de ser vendida en el mercado local, también se exporta al Ecuador, lugar donde es muy apreciada. La caballa salada se comercializa sin envasar por lo que está expuesta a contaminantes físicos, químicos y biológicos, con lo cual 
dejaría de ser apto para el consumo humano, según las exigencias de calidad del Codex Alimentarius ${ }^{3}$.

El salazonado de los alimentos cárnicos como el pescado es un método para conservarlos durante periodos más prolongados para su consumo, método que se ha utilizado desde tiempos remotos ${ }^{4}$. Tiene como objeto asegurar la penetración de la sal en el músculo para lograr deshidratar o eliminar agua intracelular del producto ${ }^{5}$, puesto que la sal introducida en el músculo del pescado ayuda a preservarlo de los procesos de descomposición bacteriana, así como retardar la actividad enzimática, ya que reduce la actividad del agua del pescado ${ }^{2}$.

En general los alimentos son perecederos, por lo que necesitan ciertas condiciones de tratamiento, conservación y manipulación, siendo la principal causa de su deterioro el ataque por diferentes tipos de microorganismos (bacterias, levaduras y mohos) ${ }^{6,7,8}$. Los pescados medianamente salados presentan mejor resistencia al ataque de bacterias y pueden -al igual que los salpresos- absorber agua y aumentar de peso cuando son remojados para su desalado ${ }^{2}$.

Existen bacterias halotolerantes así como halófilas que se desarrollan en los productos salados. El predominio de determinado grupo de bacterias depende de varios aspectos tales como $\mathrm{pH}$, temperatura, presión, oxígeno ${ }^{9}$.

En pescado salado, se han indicado bacterias como: Staphylococcus aureus, Salmonella sp., Escherichia coli, Streptococcus faecalis y Streptococcus faecium ${ }^{10}$. Por su parte, en sardina salada-seca procesada artesanalmente, se reporta la presencia de Staphylococcus aureus, Salmonella sp. $y$ Escherichia coli ${ }^{11}$, mientras que Pseudomonas salinaria y Pediococcus halophylus, se mencionan en pescado seco salado ${ }^{9}$.

Para el Instituto Tecnológico Pesquero del Perú (ITP) ${ }^{12}$, los requisitos para un buen salado de pescado son: humedad ( 43 a $52 \%$ ) y cloruro de sodio ( 18 a $22 \%$ ). Asimismo, se clasifica la calidad de la caballa de acuerdo a sus características organolépticas.

La identificación de bacterias que podrían hallarse en productos salados se puede realizar secuenciando su fragmento del gen 16S ARNr. Este gen es una sección del ADN que codifica para un polirribonucleótido de unos $1500 \mathrm{nt}$, a partir de cuya secuencia se puede obtener información filogenética y taxonómica, que conduce a conocer la secuencia de nucleótidos que la conforman,

Dicha secuencia es comparada contra bases de datos genómicas, por ejemplo GenBank, los cuales acumulan millones de secuencias de ADN para diferentes genes y organismos, a fin de poder identificar la secuencia más similar que corresponda a la especie problema $^{13,14}$.

\section{MATERIAL Y MÉTODOS}

Se adquirieron 50 ejemplares de caballa salada del mercado de abastos de Tumbes, Perú, trasladándose a un depósito estéril y aséptico en la Facultad de Ingeniería Pesquera y Ciencias del Mar de la Universidad Nacional de Tumbes.

\section{Determinación de humedad y cloruros}

Humedad. Con una balanza digital (Sartorius TE2145 con precisión $\pm 0,0001 \mathrm{~g}$ ), se pesó $5 \mathrm{~g}$ del músculo de cada ejemplar de caballa y se llevó a estufa a $105^{\circ} \mathrm{C}$ por 3 a 4 horas. La muestra se retiró de la estufa y se colocó en un desecador hasta que se enfriara. El porcentaje de humedad se obtuvo con la fórmula:

$$
\text { \%Humedad }=\frac{m_{\mathbf{2}}-m_{\mathbf{3}}}{m_{\mathbf{2}}-m_{1}} \times 100
$$

En la fórmula, $m_{1}$ es el peso del recipiente de papel aluminio; $\mathrm{m}_{2}$ : el peso del recipiente + la muestra antes del secado (en gramos) y $\mathrm{m}_{3}$ el peso del recipiente + la muestra desecada (en gramos).

Cloruro de sodio. Con la balanza digital Sartorius se procedió a pesar $2 \mathrm{~g}$ del músculo de cada ejemplar de caballa. A continuación, la muestra fue triturada en un vaso de precipitación agregándosele $100 \mathrm{ml}$ de agua destilada para homogenizar el contenido, tratando de que el músculo se disgregue completamente para liberar el volumen de $\mathrm{NaCl}$, filtrándose el contenido en un filtro whatman, para separar el músculo triturado del líquido, dejándose decantar por un minuto.

Se tomó $10 \mathrm{ml}$ del líquido y se diluyó en $100 \mathrm{ml}$ de agua destilada (dilución 1:10, factor dilución $\mathrm{f}=1 / 10$ ), luego con un dosificador, se agregó una gota de solución al $1 \%$ de fenolftaleína. Si la muestra quedó en color rosa, estuvo lista para titular, caso contrario si quedó transparente se debió agregar gota a gota solución $0,1 \mathrm{~N}$ de $\mathrm{NaOH}$ hasta que la solución se tornara ligeramente rosa. Finalmente se agregó una gota de solución de cromato de potasio al 5\%. La solución debió tornarse a un tono amarillo.

Una bureta se cargó con una solución de $0,1 \mathrm{~N}$ de $\mathrm{AgNO}_{3}$, hasta un valor exacto en la escala de la bureta (volumen inicial Vi). En un vaso de precipitados se colocó la muestra liquida con $\mathrm{NaCl}$ obtenido del músculo del pescado salado y se puso debajo de la bureta que pendía de un soporte universal.

Luego con la bureta se agregó gota a gota la solución de $\mathrm{AgNO}_{3}$, observándose primero la formación de un precipitado blanquecino de cloruro de plata $(\mathrm{AgCl})$ y finalmente la titulación terminó al producirse un precipitado color rojo ladrillo de cromato de plata $\left(\mathrm{Ag}_{2} \mathrm{CrO}_{4}\right)$. En la escala de la bureta se anotó el volumen final (Vf). El gasto (G) se determinó por diferencia entre el volumen final e inicial (Vf - Vi). Para obtener la concentración de $\mathrm{NaCl}$ se utilizó la siguiente fórmula:

$$
C_{N a C l}=\frac{G(m l) \times N_{A g N a z} \times P M_{M a C l} \times 100}{1000 \times W_{p}(g) \times f}
$$


La fórmula involucra los datos $C_{\mathrm{NaCl}}$ : concentración porcentual de $\mathrm{NaCl}$ en el músculo del pescado; $G(m l)$ : gasto en mililitros; $N_{\mathrm{AgNO}_{3}}$ : normalidad de la solución de nitrato de plata $=0,1 \mathrm{~N} ; P M_{\mathrm{NaCl}}$ : peso molecular del cloruro de sodio $=58,5 \mathrm{~g} ; f$ : factor de dilución de la solución de cloruro de sodio $=1 / 10$.

\section{Aislamiento de cepas bacterianas}

De cada caballa se extrajo una muestra del músculo de entre 0,5 y $1 \mathrm{~g}$, colocándose cada muestra en un tubo falcon de $15 \mathrm{ml}$. Las muestras se homogenizaron utilizando un macerador metálico, agregándose $5 \mathrm{ml}$ de solución salina al $10 \%$.

A partir de esta mezcla y sin realizar diluciones, se sembraron por barrido, inóculos de $100 \mu 1$ en placas petri con agar tripticase soya (TSA), incubándose a temperatura ambiente por 24 horas. De cada una de las colonias obtenidas se tomó una muestra y se volvió a sembrar en placas con agar TSA a fin de obtener una cepa más purificada.

Una vez obtenidas, las cepas purificadas se guardaron en medio sólido de agar TSA para posteriormente poder realizar la extracción del $\mathrm{ADN}$ de las diferentes cepas que se obtuvieron.

\section{Secuenciamiento de bacterias en el músculo de caballa usando un fragmento del gen $16 \mathrm{~S} \mathrm{ARNr}$}

a. Extracción del ADN. Se tomó una placa de petri en la que se cultivó en TSA con $15 \%$ de $\mathrm{NaCl}$, una cepa bacteriana aislada de la caballa, la que se dejó crecer por $72 \mathrm{~h}$. Se tomó un microtubo de centrífuga y se taró, luego se retiraron las colonias bacterianas de la placa de petri y se transfirieron al tubo, hasta que se obtuvo una masa de colonias con peso entre 14 a $20 \mathrm{mg}$.

Seguidamente se añadió al microtubo, $800 \mu \mathrm{l}$ de solución fisiológica $(0,85 \% \mathrm{de} \mathrm{NaCl})$ y se suspendieron las colonias bacterianas en la misma. Se centrifugó a 10000 $\mathrm{rpm}$ por $2 \mathrm{~min}$, luego se retiró el sobrenadante invirtiendo el microtubo. A continuación, se añadió al microtubo $500 \mu 1$ de solución de buffer de fosfato salino (PBS) $1 \mathrm{X}$, nuevamente se resuspendieron las colonias en dicha solución, posteriormente se llevó a centrifugación a $10000 \mathrm{rpm}$ por $2 \mathrm{~min}$ retirándose el sobrenadante por inversión del microtubo

Posteriormente se añadió $200 \mu \mathrm{l}$ de solución de tris EDTA (TE) 1X, nuevamente se re-suspendieron las colonias en dicha solución para lo cual se hizo uso de un vórtex. El microtubo fue 1levado a baño maría, a temperatura de ebullición $\left(95 \mathrm{a} 100{ }^{\circ} \mathrm{C}\right)$, por $10 \mathrm{~min}$, luego se colocó en congelación a $-20^{\circ} \mathrm{C}$ por $5 \mathrm{~min}$.

El microtubo se llevó a centrifugación a 10000 rpm por $2 \mathrm{~min}$. Finalmente, se tomó $10 \mu \mathrm{l}$ del sobrenadante y se llevó a un nuevo microtubo de centrífuga y se le añadió $90 \mu 1$ de agua ultrapura. Este microtubo fue llevado a congelación a $-20^{\circ} \mathrm{C}$ en un congelador.
Tabla 1. Cálculo de volumen de reactivos para la preparación del mix necesario para la realización de la PCR

\begin{tabular}{lc}
\hline reactivo & volumen $(\mu 1)$ \\
\hline agua ultra pura & 8,25 \\
solución buffer 2X premix GeneOne & 12,50 \\
$\operatorname{MgCl}_{2}(10 \mathrm{mM})$ & 2,50 \\
Primerforward 27F & 0,50 \\
Primerreverse 1492R & 0,50 \\
Taq polimerasa $(5 \mathrm{U} / \mu 1)$ & 0,25 \\
\hline total & 24,50 \\
\hline
\end{tabular}

$x$ incluye dNTPs, pero no incluye $\mathrm{MgCl}_{2}$ (cat ${ }^{\circ} \mathrm{S} 113$ ).

Tabla 2. Porcentaje de humedad y $\mathrm{NaCl}$ del músculo de los ejemplares de caballa en los meses muestreados.

\begin{tabular}{lccc}
\hline muestreo & $\mathrm{N}^{\circ}$ ejemplares & humedad (\%) & $\mathrm{NaCl}(\%)$ \\
\hline junio & 15 & $62,73 \pm 3,02$ & $12,62 \pm 4,92$ \\
agosto & 20 & $62,72 \pm 10,34$ & $15,31 \pm 3,01$ \\
setiembre & 15 & $47,71 \pm 5,53$ & $11,87 \pm 4,67$ \\
\hline
\end{tabular}

Humedad y $\mathrm{NaCl}$ figuran en promedio \pm desvío estándar.

b. Amplificacióndel fragmento del gen $16 \mathrm{~S}$ ARNr. Se usaron los iniciadores 27F (5'-AGAGTTTGATCMTGGCTC-3') y 1492R (5'-GGTTACCTTGTTACGACTT-3'), los cuales producen una amplificación de $1465 \mathrm{pb}{ }^{15}$. La amplificación se realizó preparando una solución mix para realizar la reacción de PCR, teniendo en cuenta el número de cepas bacterianas a las cuales se les extrajo el ADN. A estos, se les adicionó una reacción más para el control negativo y otra para el control positivo (Tabla 1).

La amplificación del ADN se realizó en un termociclador (marca Applied Biosystems modelo SimpliAmp termal Cycler) que fue programado basado en el protocolo utilizado por Pérez ${ }^{17}$, que consiste en: i) predesnaturalización a $95^{\circ} \mathrm{C}$ por $1 \mathrm{~min}$; ii) 30 ciclos de las siguientes etapas: $94^{\circ} \mathrm{C}$ por $30 \mathrm{~s}$ (desnaturalización), $50^{\circ} \mathrm{C}$ por $40 \mathrm{~s}$ (hibridación) y $68^{\circ} \mathrm{C}$ por $30 \mathrm{~s}$ (polimerización); e iii) polimerización final a $68^{\circ} \mathrm{C}$ por $7 \mathrm{~min}$.

Para la verificación de la amplificación, se hizo migrar los amplicones en geles de $120 \mathrm{ml}$ de agarosa al $2 \%$ conteniendo $5 \mu$ de bromuro de etidio, se usó como tampón de migración TAE 1X. En los pozos de dichos geles se colocó $1 \mu \mathrm{l}$ de tampón de depósito y $9 \mu \mathrm{l}$ de cada amplicón. La migración se realizó a $68 \mathrm{~V}$ durante $45 \mathrm{~min}$.

Conjuntamente se hizo migrar un marcador de peso molecular de 100 a $3000 \mathrm{pb}$. Los geles fueron visualizados utilizando un transiluminador (marca Spectroline, modelo 3494-3123).

\section{c. Identificación de cepas bacterianas aisladas} de caballa salada. La bacterias aisladas del músculo de caballa fueron identificadas mediante búsqueda de secuencias similares en la base de datos GenBank, siendo el criterio para identificar la cepa a nivel de especie, al menos $99 \%$ de similitud con la secuencia com- 
Tabla 3. Especies bacterianas identificadas en caballa salada según búsqueda de su secuencia nucleótida en GenBank.

\begin{tabular}{|c|c|c|c|c|c|c|}
\hline \multirow[b]{2}{*}{ cepa } & \multirow{2}{*}{$\begin{array}{l}\text { especie } \\
\text { identificada }\end{array}$} & \multicolumn{5}{|c|}{ secuencia más similar en GenBank } \\
\hline & & especie & $\begin{array}{c}\text { cobertura } \\
(\%)\end{array}$ & $\begin{array}{c}\text { identidad } \\
(\%)\end{array}$ & E-value & $\begin{array}{l}\mathrm{N}^{\circ} \text { acceso } \\
\text { GenBank }\end{array}$ \\
\hline$\overline{3}$ & Staphylococcus sp. & Staphylococcus equorum & 99 & 97,43 & $0,0 \mathrm{E}+00$ & MG598457.1 \\
\hline 4 & Halomonas sp. & Halomonas sp. & 98 & 97,06 & $0,0 \mathrm{E}+00$ & MK256716.1 \\
\hline 5 & No identificada & Salinivibrio costicola subsp. vallismortis & 39 & 93,85 & $3,0 \mathrm{E}-68$ & AB617566.1 \\
\hline 6 & Staphylococcus sp. & Staphylococcus sp. & 100 & 99,73 & $0,0 \mathrm{E}+00$ & MK534048.1 \\
\hline 8 & Staphylococcus equorum & Staphylococcus equorum & 100 & 100,00 & $0,0 \mathrm{E}+00$ & MK696401.1 \\
\hline 9 & No identificada & Salinivibrio sp. & 100 & 90,26 & $0,0 \mathrm{E}+00$ & MK622852.1 \\
\hline 10 & Salinivibrio sp. & Salinivibrio sp. & 100 & 100,00 & $0,0 \mathrm{E}+00$ & MK070917.1 \\
\hline 11 & Staphylococcus sp. & Staphylococcus sp. & 100 & 99,64 & $0,0 \mathrm{E}+00$ & MK534048.1 \\
\hline 12 & Staphylococcus nepalensis & Staphylococcus nepalensis & 100 & 99,47 & $0,0 \mathrm{E}+00$ & MK602316.1 \\
\hline 13 & Staphylococcus equorum & Staphylococcus equorum & 100 & 99,47 & $0,0 \mathrm{E}+00$ & MK696401.1 \\
\hline 14 & Salinivibrio sp. & Salinivibrio sp. & 100 & 99,52 & $0,0 \mathrm{E}+00$ & MK070915.1 \\
\hline 15 & Staphylococcus equorum & Staphylococcus equorum & 99 & 100 & $0,0 \mathrm{E}+00$ & NR_027520.1 \\
\hline 16 & No identificada & Staphylococcus sciuri & 92 & 81,82 & $4 \mathrm{E}-148$ & CP020377.1 \\
\hline
\end{tabular}

parada; mientras que para identificar a nivel de género, que tenga al menos una similitud de $97 \%$.

\section{RESULTADOS}

Porcentaje de humedad y cloruro de sodio en el músculo de los ejemplares de caballa salada. El porcentaje promedio de la humedad del músculo de los ejemplares de caballa tuvo un valor mínimo de $32,13 \%$ y un máximo de $70,94 \%$, mientras que el porcentaje de $\mathrm{NaCl}$ estuvo entre 11,87 y $15,31 \%$, con un rango de concentraciones entre 5 y $25,5 \%$. Ambos se muestran en la Tabla 2.

Identificación de cepas bacterianas aisladas de caballa salada. La Tabla 3 muestra las especies bacterianas que se identificaron mediante la búsqueda de secuencias similares en la base de datos GenBank, determinándose 13 cepas de las que fue posible obtener secuencias de ADN.

Las cepas que fueron posibles de identificar pertenecieron a sólo tres géneros: Staphylococcus (siete cepas), Salinivibrio (dos cepas) y Halomonas (una cepa). Sólo cuatro cepas pudieron ser identificadas a nivel de especie, todas ellas del género Staphylococcus, siendo ellas: S. equorum (tres cepas) y S. nepalensis (una cepa).

\section{DISCUSIÓN}

Las cepas bacterianas que fueron identificadas mediante secuenciación y búsqueda en la base de datos Genbank correspondieron a géneros y especies reportados previamente como flora bacteriana halófila, como: Staphylococcus sp., Staphylococcus nepalensis, Staphylococcus equorum, Salinivibrio sp. y Halomonas $\mathrm{sp}{ }^{16,17}$ han reportado presencia de varias cepas de Staphylococcus sp., entre ellas $S$. nepalensis y $S$. equorum en corvinas saladas y fermentadas en China, así como en mariscos salados en Corea, siendo por tanto especies que forman parte de alimentos con alto contenido de sal.

Adicionalmente, en una guía de calidad de caballa salada, se señala que las bacterias antes indicadas forman parte de la flora de este producto ${ }^{12}$. Por su parte, se menciona que en alimentos fermentados y con alto contenido de sal, se identificaron Staphylococcus equorum como especie dominante ${ }^{18}$. Esta bacteria productora de aminas, también se ha detectado con frecuencia en productos cárnicos fermentados con alto nivel de sal en Europa.

Entre las aminas biogénicas, la histamina y la tiramina son peligrosas para la salud humana debido a sus propiedades vasoactivas y psicoactivas, aunque ninguna de las enzimas implicadas en la descarboxilación de histidina y tiramina fueron identificadas en los genomas de las cepas de S. equorum.

Por otra parte, Halomonas sp. han sido reportadas como parte de la flora bacteriana de mariscos salados en Corea ${ }^{17}$, mientras que Salinivibrio sp. ha sido encontrada como flora bacteriana de productos de pescado salado ${ }^{19}$. También se afirma que Salinivibrio es un género bacteriano capaz de vivir en concentraciones de $\mathrm{NaCl}$ de 0,5 a $20 \%{ }^{20}$, lo que le faculta a desarrollarse en ambientes hipersalinos y en carnes saladas.

En resumen, todas las especies bacterianas identificadas en esta investigación corresponden a géneros presentes en productos con alto contenido de sal. En esta investigación, la humedad porcentual promedio se encontró en $62,73 \pm 3,02 \%$ en junio; $62,72 \pm 10,34 \%$ en agosto y $47,7 \pm 5,53 \%$ en septiembre, coincidiendo con lo mencionado por quienes refieren que un buen pescado salado debe contener entre 45 y $52 \%$ de humedad ${ }^{12}$.

En el caso de este trabajo, solo 15 de los 50 ejemplares analizados (30\%) estuvieron dentro del rango manifestado por investigadores ${ }^{12}$, con lo cual el $70 \%$ 
restante no tuvo una humedad adecuada, lo cual genera que dichos productos reduzcan su vida en anaquel.

En el presente trabajo la concentración de $\mathrm{NaCl}$ en el músculo de caballa salada estuvo entre de $11,87 \pm 4,67 \%$ y $15,31 \pm 3,01 \%$, valores inferiores al recomendado por el ITP (2001) quien indica que un buen músculo de pescado salado debe contener entre $18 \%$ y $22 \%$ de $\mathrm{ClNa}$. Ello difiere contra quienes manifiestan que al $15 \%$ de $\mathrm{NaCl}$ no hay crecimiento de Staphylococcus nepalen$s i{ }^{21}$, mientras que hasta un $10 \%$ sí lo hay.

En conclusión, mediante la secuenciación de un fragmento del gen 16S ARNr y la búsqueda en la base de datos Genbank, se determinaron las especies: Staphylococcus sp, Staphylococcus equorum, Staphylococcus nepalensis, Salinivibrio sp y Halomonas.

Agradecimientos. Se agradece a la Facultad de Ingeniería Pesquera y Ciencias del Mar de la Universidad Nacional de Tumbes, Perú, por permitir el desarrollo del presente proyecto en sus instalaciones. Asimismo, se agradece al Instituto del Mar del Perú-Laboratorio costero Tumbes, por facilitar el uso de algunos de sus equipos.

\section{REFERENCIAS}

1. Balbuena ED. 2014. Manual básico sobre procesamiento e inocuidad de productos de la acuicultura. Minist. Agric. Ganad. Paraguay. On line: http://www.racua.net/upload medManual_procesamiento_PY.pdf.

2. Condori Ch. 2014. Deterioro y Conservación de Alimentos. Tesis para optar por el titulo de Ingeniero de Industrias Alimentarias. Univ. Nac. San Agustín, Fac. de Ing. de Procesos, Escuela Prof. de Ing. de Industrias Alimentarias, p. 143

3. Delacruz S y Roncal J. 2014. Conservación de alimentos mínimamente procesados. Tesis p'optar titulo Ing. Quimico, Univ. Nac. Trujillo, Fac. Ing. Quím., Perú. 119 p.

4. Dulanto JR. 2013. Identificación rápida de especies del género Vibrio asociados con el cultivo de "langostino blanco". Tesis Biologia, Univ.Nac.Mayor San Marcos, 109 p.

5. Escobar KE y Hernández C. 2012. Análisis de bacterias patógenas en Sardina Salada-Seca. Tesis p/Licenciat. Biologia, Univ.El Salvador, Escuela Biología,124 p.

6. Guzman K. 2017. Calidad en la logística de alimentos perecibles. Titulación por examen profesional. Univ. Nac. Agraria Molina, Facult. Industr. Aliment., 52 p.

7. Grau C, Elguezabal L, Vallenilla O., Zerpal A. 2003. Evaluación de la flora microbiana halófila contamínate del pescado seco-salado. Instit.Univ.Tecnol. Cumaná, Venezuela. Rev Cient FCV-LUZ 13: 319-325.
8. Guan L, Cho KH, Lee JH. 2011. Analysis of the cultivable bacterial community in Jeotgal. Food Microbiology 28: 101-103.

9. INEI (Instituto Nacional de Estadística e Informática). 2014. Compendio Estadístico Perú 2014. Lima, Perú. On line: https://www.inei.gob.pe/media.

10. ITP (Instituto Tecnológico Pesquero del Perú). 2001. Guía para la instalación y operación de establecimientos dedicados al salado del pescado. Perú.

11. Jonghoon L, Sojeong H, Dowon J. 2018. Genomic insights into Staphylococcus equorum KS1039 as a potential starter culture for the fermentation of high-salt foods. BMC Genomics 19: 136.

12. León E. 2011. Muestreo estacional del contenido graso en músculos de "caballa" Scomber japonicus. Tesis para obtener grado de Biología, Univ. Nac. Callao, 98 p.

13. López L, Dávila L. 2005. Salado de merluza por pila seca, húmeda y por deshidratación osmótica a vacío Merluccius gayi peruanus). Industrial data 8: 2.

14. López C. 2017. Análisis filogenético y genómico del género Salinivibrio. Tesis Doctoral, Universidad de Sevilla. $338 \mathrm{p}$.

15. López HC, Haba RR, Sánchez PC, Ventosa A. 2018. Salinivibrio Kushneri sp, a moderately halophilic bacterium isolated from salterns. Systematic and Applied Microbiology 41: 159-66.

16. OMS (Organización Mundial de la Salud). 2018. Codex alimentarius. Normas internacionales de los alimentos. On line:http://www.fao.org.pdf.

17. Pérez LM. 2005. Variabilidad genética de cepas nativas de Azospirillum brasilense mediante análisis tipo PCRRFLP del DNA 16S ribosomal. Tesis para optar al grado de Maestro en Biotecnología Genómica. Inst.Politéc.Nac., Reynosa, México, 107 p.

18. Romero JJ, Negrete RM. 2011.Presencia de bacterias gram positivas en músculo de pescado con importancia comercial en la zona del Caribe mexicano. Revista Mexicana de Biodiversidad 82: 599-606.

19. Rodicio M, Mendoza M. 2004. Identification of bacteria through 16S rRNA sequencing: principles, methods and applications in clinical microbiology. Enferm Infec y Microbiol Clinica 22: 238-245.

20. Spergser J et al. 2003. Staphylococcus nepalensis sp Nov, isolated from goats of the Himalaya region. Internat J Systemat \& Evolut Microbiol 53: 2007-2011.

21. Zhang $\mathbf{H}$ et al:: 2015. Microbiological changes and biodiversity of cultivable indigenous bacteria in Sanbao Larger Yellow Croaker (Pseudosciaena crocea). J of Food Sci 80 : 4 (M776-M781). 